\title{
El no lugar de la música indigenista en Chile: hacia una etnomusicología de la soledad
}

\section{The Non-place of the Indigenous Music in Chile: towards an Ethnomusicology of Loneliness}

\author{
Rafael Díaz Silva \\ Pontificia Universidad Católica de Chile, Facultad de Artes. Santiago, Chile \\ Universidad de Chile, Facultad de Artes. Santiago, Chile \\ rdiazs@uc.cl
}

Resumen - El artículo se centra en el estudio de los nuevos espacios que surgen en la sociedad contemporánea, para manifestaciones musicales adscritas a los pueblos originarios de Chile. Se sostiene que, junto con la diáspora socio-estética de la performática musical indígena, se ha producido paralelamente el desplazamiento de sus espacios rituales hacia sitios en donde ninguna actividad artística había encontrado su lugar antes del advenimiento de la sobremodernidad. Esta reconfiguración espacial ofrece nuevos retos para la etnomusicología. Ya no sólo se trata del desafío de estudiar nuevas formas de arte étnico en un contexto intercultural, sino también de incluir el complejo parámetro del lugar antropológico, que modifica los aspectos (y espectros) del arte oral y que resitúa al investigador en una nueva coordenada, la del «no-lugar».

Palabras claves: música indígena, no-lugar, sobremodernidad, coordenada, oralidad.

Abstract - The article focuses on the analysis of the new cultural places raised within contemporary society, which affects musical expressions attached to aboriginal cultures in Chile. The article claims that, next to the socio-aesthetical Diasporas of indigenous musical performance, a parallel shift is being produced, from ritualistic places to spaces where no artistic expressions had been before hypermodernity. This reconfiguration of space is a new challenge to Ethnomusicology because nowadays, not only the study of new forms of ethnic art in an intercultural context is required, but also the inclusion of the anthropological place. This modifies the aspects (and specters) of oral art and relocates the researcher in a new coordinate, the "non-place».

Keywords: indigenous music, non-place, hypermodernity, coordinate, orality. 
La presencia del aborigen en el contexto socio-cultural chileno ha desencadenado una serie de interpelaciones y negociaciones musicales (Vila, 2000), las que, pese a la pertinaz negación de una parte de la historiografía chilena, ya no resultan posible ocultar ni menoscabar. La fuerte incidencia de los pueblos originarios en la cultura criolla, está generando mutaciones insospechadas en el campo de las artes en general y particularmente en la música, así lo dejan ver los productos estéticos mestizos generados a partir del patrimonio cultural indígena. Sin embargo, esta camaleónica fractalidad musical se está produciendo en un tiempo y un espacio profundamente modificado por los nuevos regímenes sociales. Estamos en un tiempo saturado de acontecimientos, por el pulso acelerado de los eventos en una sociedad sobreinformada. En relación al espacio, nos enfrentamos ante la proliferación de nuevos habitares que acogen el arte musical de raíz y que juegan a reestablecer el centro perdido de las culturas originarias, hoy en tránsito por el territorio nacional. El «no-lugar» de la sociedad actual es aquel espacio momentáneo, fugitivo y transitorio que le brinda al arte una comunidad, o una "tribu», a quien dirigirse y con quienes generar una complicidad.

Estos «no-lugares», de algún modo ocultos, pero abiertos a la vez, a todo el mundo, conservan algo de aquella interdicción que caracteriza a los lugares sagrados precolombinos. Ya no es la turbera prohibida para el kaweskar, ni el sitio sagrado del rewe mapuche, que impone un límite para la aproximación del buinka. ${ }^{1}$ Ahora es el espacio encantado de la instalación, cuyas fronteras sólo los que conocen sus códigos rebasan, o es la performance a la que se accede sólo por invitación, o, más restringido aún, es el espacio del ritual privado, y el de la protesta, los lugares de encuentro y de centro para desplegar la ritualidad del sonido indigenista, un sonido en trance hacia esa arcaica espiritualidad anterior a la cruz. Resulta interesante conjeturar sobre la posible relación entre estos espacios ocultos o disimulados y las posibles razones del «ocultamiento de sujetos sociales en Chile» (Rondon, 2000: 2), como el caso del mapuche, cuya incidencia en la cultura chilena es inversamente proporcional a su presencia en la teoría cultural de Chile, y que, dentro de la estructura de este artículo, juega el papel de encarnar una hipótesis socio-estética de fondo: una posología del mestizaje condicionada por la narrativa social y configurada internamente por la expansión-contracción del espacio público, aquel susceptible de ser ocupado por la performática musical aborigen.

\section{UNA FILIACIÓN DE LO ALÓCTONO}

Se ha discutido mucho sobre los procesos de maduración de una sociedad que se abre a discursos estéticos nuevos o revisitados. La interpelación del indigenismo, polifónico y polisémico en su momento, forjó una articulación de sentido, cuya experiencia emocional reflejaba las necesidades de un Chile de los años cuarenta, que consolidaba la llamada "pacificación de la Araucanía».

También surgía en las urbes, una clase media harta de exclusión y del gusto aristocrático. Con el auge de la burguesía y su creciente consumo de arte hecho a su medida, avanzamos hacia un proceso de des-sacralización y de des-elitización del arte, lo que

Término con que el mapuche designa al criollo, es decir, el chileno de sangre española nacido en territorio chileno. 
vuelve necesario, por un lado, abrir el arte hacia otros modos de creencias, y a la vez, popularizar y trivializar los modos artísticos de la clase aristocrática.

El «otro», y su música, en los años treinta del siglo pasado, era un modo saludable, fresco y sano de declarar pertenencia (aunque sea parcial) a una cultura marginal que tenía la propiedad de empatizar especialmente con la clase media chilena y sus ideales de igualdad. Se trataba pues, de una situación de identificación en la cual el mapuche tenía su interpelación ganada. Hoy en día el caso tiene otras complejidades, pero los mecanismos sociales en juego son homologables con los de los años treinta. Esta vez, la des-elitización del arte académico no es consecuencia del ascenso de una clase media, sino del ascenso de la mass media, la cual penetra todo sistema cultural con la web, popularizando la aldea global del mundo y sus etnicidades. Súbitamente el marginal, el "excéntrico", asciende a un posicionamiento cultural masivo porque su propio carácter minoritario lo vuelve objeto del deseo para la red global que todo lo conoce y lo difunde. Con la masificación de las diferencias y las minorías, se produce el efecto contrario: la sobre-reacción de las minorías para defender lo propio (en la imposibilidad de poder seguir sosteniendo los límites) y la necesidad consiguiente de tener un referente cultural unívoco y distinguible, como defensa ante una oferta desmesurada y desquiciada de arquetipos de identidad estéticos.

Según Isamitt ${ }^{2}$ (1935), las diferencias psicológicas entre el mapuche y el criollo no han permitido nunca enlazar ambas culturas. Sin embargo, en opinión de Juan Pablo González «el mundo mapuche ha sido de alguna manera incorporado a la conciencia histórica del chileno, quien ha desarrollado diferentes interpretaciones y actitudes frente a él» (1993: 78).

Una serie de interrogantes surgen de esta negociación aborigen-criolla: ¿cómo el chileno urbano observa, interpreta y responde a la cultura indígena en cuyos territorios ancestrales habita?, ¿ha desarrollado este habitante una cultura mestiza mediante la práctica musical de raíz indígena?, ¿qué características sociales y estéticas tendría esa práctica musical?

Primero el español y luego el chileno, le han otorgado al aborigen estereotipos de identidad de acuerdo a un conjunto de rasgos concebidos, en algún momento histórico, como importantes y auténticos (Ochoa, 2002; Stuchlik, 1973).

La música chilena académica de ascendencia indígena, ha contribuido a crear, sustentar y modificar esos estereotipos. A través del siguiente esquema, podremos visualizar mejor las tensiones que se forman al contrastar estos imaginarios musicales de identidad dentro de un sistema interdependiente:

2 El compositor, investigador y violinista chileno Carlos Isamitt (1887-1974) desarrolló una fecunda labor de recopilación, transcripción y reutilización de música mapuche, específicamente entre 1931 y 1937. 


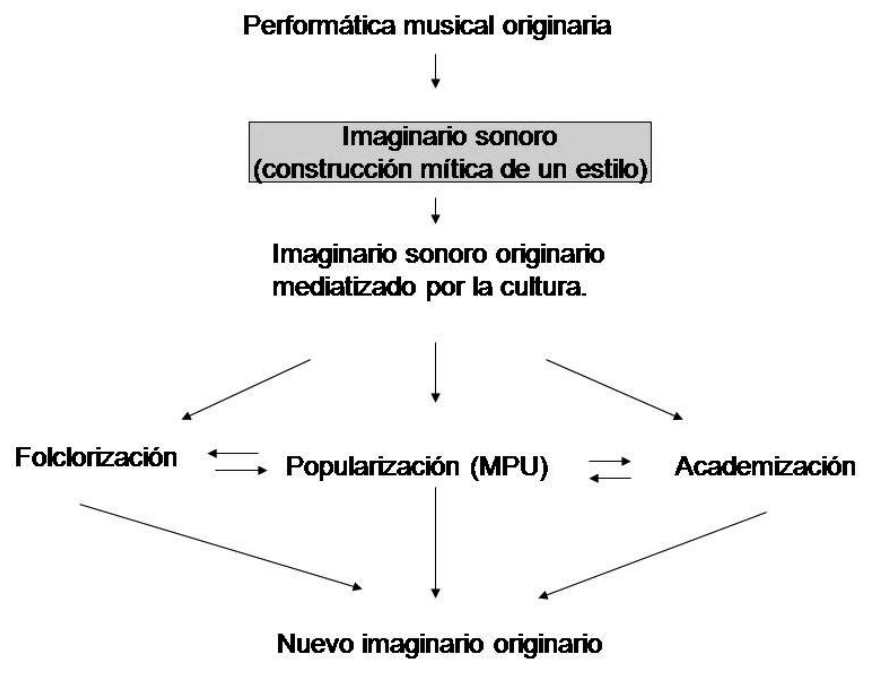

Imagen 1.

Es innegable que, para el investigador de hoy, las condiciones de accesibilidad a esa performática musical originaria son casi nulas, debido a que los registros sonoros son pocos y de una extensión diacrónica limitada y acotada. Sin embargo, las investigaciones emprendidas desde principios del siglo XX en adelante, así como los registros compilados desde entonces, permiten configurar un corpus que nos sitúa cómodamente en el segundo estadio: «imaginario sonoro». Es decir, la información que se dispone es material suficiente como para edificar una construcción más o menos mítica de un acervo musical que nos viene de muy lejos y cuyos destellos, como la luz de las estrellas ya extintas del universo, nos alcanzan a pesar de que su fuente de origen ha dejado de existir. Esta construcción mítica de una performática originaria difusa, sufre a su vez la acción modeladora y dislocadora de tres agentes socio-musicales vigentes en el siglo XXI, no sólo en Chile, sino en el mundo occidental. Ellos son, el folclor, las músicas populares y la música académica contemporánea. De los tres, el más fuerte lejos, es aquel de la MPU, ${ }^{3}$ por su poder de atracción en las masas, y, por lo tanto, por su capacidad de ofrecer símbolos de identidad y de pertenencia a los miembros de una comunidad determinada. El folclor no posee la misma proyección masiva que la MPU, pero sí es tan fuerte como ella en la capacidad de interpelar y generar complicidades afectivas entre sus seguidores. Sin duda, el agente más débil en este juego de contrafuerzas, es el de la música académica contemporánea, un producto cultural que se ha radicalizado en su condición de artículo suntuario y críptico dentro de la sociedad contemporánea. Sin embargo, este último, ha sabido sobrevivir, no gracias a lo que fue como género antes del advenimiento de la postmodernidad, sino que a través de las influencias de los otros dos agentes más poderosos,

\footnotetext{
MPU, músicas populares urbanas.
} 
que han permeado hacia el campo de lo académico, y que, al hacerlo, han revitalizado una línea de música que parecía marchar directamente hacia su desaparición, lo que es igual que decir que volvía a ser patrimonio de los reducidos círculos de las academias y universidades, un pequeño ghetto dentro del sobrepoblado vecindario de la sobremodernidad. ${ }^{4}$ Es innegable también que estas tres fuerzas, al interactuar entre sí y sin importar la fuerza gravitatoria con que actúa cada cual, están conformando hoy en día lo que en el futuro podremos llamar «la música originaria». Es decir, un nuevo relato de identidad musical cuyas raíces se pierden en el tiempo, y que, actualmente, se encuentra en una etapa vertiginosa de desmantelamiento y de-construcción, cuyos alcances no podemos predecir. Sí se puede augurar que este nuevo imaginario indígena llegará a legitimarse y establecerse como un paradigma de lo originario, no importando su condición mestiza y acéntrica. De alguna manera, es un fenómeno socio-cultural que Stuart Hall predice dentro de su amplia definición de Identidad como: «la producción en el futuro de un relato del pasado, es decir, como algo referido a una narración y al relato que realizan las Culturas para explicarse quiénes son y de dónde vienen» (1992: 5). O sea, la identidad como un relato del que no vale la pena preguntarse por su autenticidad, porque basta que construya un pasado que le sirva a un grupo cultural para ponerse de pie con la cabeza erguida. En términos culturales, a quién le importa la verdad, es tener una idea de sí mismo (y del «otro») que nos permita la ilusión del origen y la pertenencia, y para ello, la música (o mejor dicho, las músicas, en clave de sobremodernidad) es el mejor espejismo de las sociedades que han perdido el espejo de su pasado.

\section{EL INDIGENISMO ERRANTE DE LA SOBREMODERNIDAD}

Con el resurgimiento, en nuestros días, de una narrativa musical indigenista en Chile, otra terminología y otras especificidades técnicas aparecen, todas, como consecuencia de la pérdida de un centro unívoco de irradiación cultural y por la imposibilidad de sustraerse a la inmediatez del tempo contemporáneo. Sin embargo, necesariamente debemos vincular esta narrativa con el imaginario indigenista de los años treinta y cuarenta. El caso de la música chilena de raíz en el siglo XXI, es esencialmente en mi opinión, una proyección intercultural de esa antigua dialéctica, y que adquiere algunas características radicales, si se las compara con el contexto antiguo, pero que resultan explicables a la luz del nuevo juego de interpelaciones y negociaciones que se establecen entre la creación musical chilena y la sociedad chilena post y sobremoderna. En el cuadro siguiente, podemos ver cómo el fenómeno de la música académica con raíz en Chile, sufre un cisma radical con el advenimiento de la interculturalidad en los ochenta en el mundo:

Augé define la sobremodernidad como una situación de exceso o abundancia, «es pues con una figura del exceso - el exceso de tiempo- con la que definiremos primero la situación de sobremodernidad [...]. Desde el punto de vista de ella, la dificultad de pensar el tiempo se debe a la superabundancia de acontecimientos del mundo contemporáneo [...] La segunda figura del exceso característica de la sobremodernidad, corresponde al espacio. Del exceso de espacio podríamos decir en primer lugar, aquí otra vez un poco paradójicamente, que es correlativo del achicamiento del planeta: de este distanciamiento de nosotros mismos al que corresponden la actuación de los cosmonautas y la ronda de nuestros satélites" (2008: 36). 


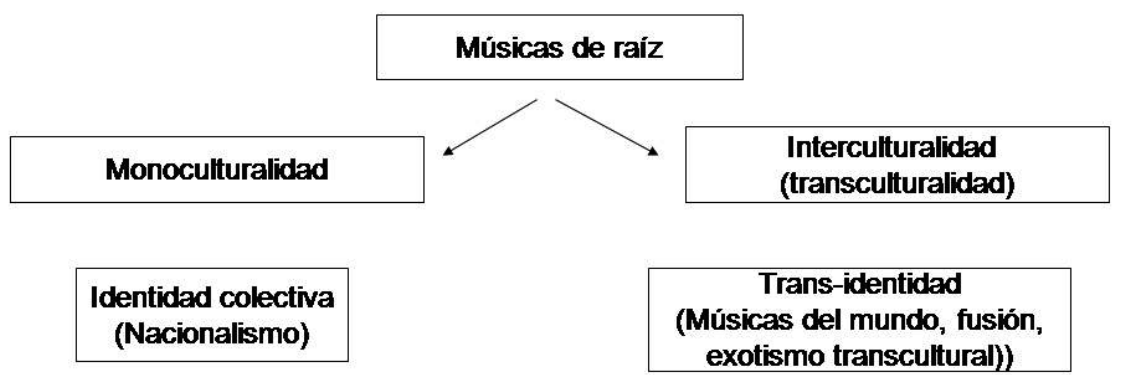

\begin{tabular}{|c|}
\hline Escritura estilemática \\
Sintagma-estilema
\end{tabular}

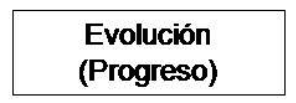

\section{Música académica para salas de concierto}

\section{Escritura musémica} Sigma del sintagma

Involución (des-progreso)

Imagen 2. Cisma dicotómico de la música académica de raíz.

La música indigenista chilena resultó fuertemente afectada por el derrumbe del paradigma monocultural hacia fines del siglo XX, fundamentalmente por el advenimiento de la era Internet y la desaparición de los espacios geográficos autocontenidos, que, en los tiempos de la monoculturalidad, conservaban a las culturas autónomas dentro de territorios soberanos, con límites establecidos. Esta situación era propia de los tiempos de Isamitt, el mapuche todavía vivía en reducciones. En los tiempos actuales, el mapuche está incorporado a la sociedad chilena y convive con el criollo "codo a codo" (Díaz, 2008). O sea, las culturas autónomas, homogéneas y autocontenidas dentro de territorios (soberanos), con fronteras bien delimitadas, son entidades e identidades (aparentemente) en vías de disolución (Guilbaut, 1993). Por su parte, Michel de Certeau (1990), habla de las "astucias» de las artes de hacer, que permiten a los individuos sometidos a las coacciones globales de la sociedad moderna, especialmente las de la sociedad urbana, desviarlas y re-utilizarlas por efecto de una especie de desmontaje de los objetos inertes de lo cotidiano, para trazar en ella su decoración y sus itinerarios particulares. Los nacionalismos y los latinoamericanismos (la expresión nacionalista en Latinoamérica), engendrados por sistemas culturales excluyentes, fuertemente enraizados en el concepto de la pureza identitaria y en la tradición, produjeron en el campo de la música, un recurso composicional clave para poder aludir al material musical con raíz: el estilema, es decir, un melotipo y/o ritmotipo que se asocia a un estilo susceptible de relacionar con la música de las culturas originarias. Este recurso, no cumplía un rol estructural profundo, sino que funcionaba más bien con el rol de cita o como una inserción más o menos postiza dentro de una superestructura predominantemente centro-europea. Es el caso de obras como Evocaciones Huilliches (1945) del chileno Carlos Isamitt, o de su compatriota Roberto Falabella 
en sus Estudios Emocionales (1957). Por tanto, el elemento musical indígena lo veremos casi siempre subordinado a una técnica de organización sonora y temporal que procedía de lo que se creía era la «vanguardia» en el Chile de los treinta y de los cincuenta (para mencionar dos hitos temporales de producción indigenista chilena). Es sabido que, desde la escuela de Darmstadt en adelante, el concepto de "vanguardia» se ha asociado tradicionalmente con la noción de progreso o evolución, ${ }^{5}$ ya que la teoría desarrollada sobre el tema intenta relacionar a la música y a la ciencia con el mismo objetivo terminal: acercarse, a través de un proceso progresivo de reducciones, a una escritura musical que posea un valor de mayor abstracción y complejidad con respecto a la generación anterior, y la expresión de esa nueva conquista intelectual de la escritura es llamada «vanguardia». La música chilena de raíz, no obstante su afán identitario, fue siempre condicionada por esta noción de progreso, expresada a través de una escritura que buscaba conciliar los materiales de la música indígena con los adelantos técnicos de la contemporaneidad musical del momento, ${ }^{6}$ pero los términos de esa negociación entre las dos tradiciones, siempre fue desigual, o, en otros términos, con las conquistas técnicas de la vanguardia como el dato preponderante a la hora de establecer estrategias composicionales.

Con la interculturalidad, otras formas de negociación se establecen. Ahora el dato cultural originario posee un doble tratamiento: puede ser abordado con un valor estructural profundo, lo que lleva a la escritura de radicales etnotextos musicales, ${ }^{7}$ o puede ser fusionado dentro de otros elementos musicales de culturas diversas y ser tratado con valores estructurales de superficie. ${ }^{8}$ La interculturalidad está generando música indigenista con muy poca vinculación a las vanguardias, y, por el contrario, está más atenta a lo que se produce en el campo de las músicas populares urbanas (especialmente las músicas de fusión y las incidentales para medios masivos) y en el folclor de material indígena (la folclorización de la música aborigen) que en lo que se produce en la música académica contemporánea. Es, por tanto, una música indigenista en des-progreso, o en involución, si la juzgamos bajo el precepto de Darmstadt, y en donde el musema se constituye como el recurso fundamental para configurar escrituras intergenéricas, por su condición de mensaje de valor semiótico unificado, que lo vuelve comprensible para las comunidades, y, por tanto, imprescindible para producir complicidades identitarias entre la música de raíz y la sociedad que la acoge. El resultado es una música sin status de género, por desplazarse de los cánones de la

Con respecto a la noción de progreso, Monjeau dice «el director y teórico René Leibowitz [...] intentó aislar y definir con cierta precisión los términos de un progreso histórico en la música occidental. En su libro La evolución de la música de Bach a Schoenberg (Leibowitz, 1957) intenta demostrar cómo la música comprendida en ese período transita de lo simple a lo complejo en un sentido acumulativo. Si bien la premisa de Leibowitz es discutible, no se le puede dejar de agradecer que haya despejado un malentendido muy común, según el cual la música de Bach sería más compleja que la de los clasicistas Mozart y Haydn debido a la complejidad de su polifonía. Leibowitz señala la estrechez de un criterio bastante popular entre la crítica, que consiste en medir distintos grados de complejidad de acuerdo con la dimensión exclusiva de la polifonía lineal, aunque no deja de incurrir inmediatamente en un error muy parecido al que denuncia: la suposición de una mayor complejidad de Mozart sobre Bach a partir del criterio, también excluyente, del plan tonal desarrollado en uno y otro caso» (Monjeau, 2004: 43); "la idea de progreso convoca de inmediato el paralelismo entre arte y ciencia, que la música de los últimos cien años tal vez ha reforzado a causa de la devaluación del concepto de gusto y de la pérdida de lazos con el público» (Monjeau, 2004: 27).

6 Los que, en los años cuarenta y cincuenta del siglo pasado, siempre llegaban con largo efecto retardado con respecto a Europa.

El caso de Cantos Ceremoniales para Aprendiz de Machi (2004), de Eduardo Cáceres.

8 El caso de Rogativa (1996), de Gabriel Matthey. 
música contemporánea, y por tanto, pasa a habitar un lugar socio-estético de tránsito, no tradicional ni permanente, un «no-lugar», en la definición de Augé. ${ }^{9}$

\section{MÚSICA PARA NINGÚN ESCENARIO}

Los «no-lugares» para la música de raíz, coinciden con la pérdida de un centro fijo para las músicas de los pueblos originarios. La diáspora de los grupos minoritarios de Chile aunado a esa otra pequeña diáspora del género musical contemporáneo que busca ser el Otro para dejar de ser el (excluyente) Nosotros, instaló el territorio de la performática musical, otrora destinado al espacio ritual de la gran intemperie, en el pequeño espacio de la sala de concierto, y de ahí, a la calle y al espacio ilusorio de la instalación, que no existe más allá del espacio que ocupa y se desvanece apenas abandonamos sus límites:

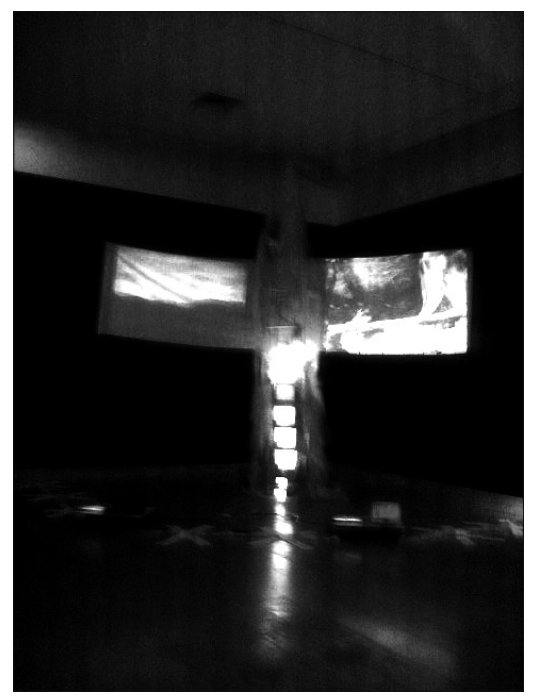

Instalación Tierra dañada. Segunda bienal de arte indígena. Centro Cultural La Moneda. Octubre 2008. Música: Cristián López.

Aparentemente, la propia crisis de la música llamada "culta» o "contemporánea», cuya razón de ser no proviene de la sociedad, que no la demanda ni la requiere, y la propia crisis de la institución del concierto, que responde a una forma de transmitir arte to-

\footnotetext{
Augé define el término «no-lugar», basado en una oposición con el lugar antropológico, «[...] el lugar antropológico es, al mismo tiempo principio de sentido para aquellos que lo habitan y principio de inteligibilidad para aquel que lo observa [...]. Estos lugares tienen por lo menos tres rasgos comunes. Se consideran [o los consideran] identificatorios, relacionales e históricos» (Augé, 2008: 58); "si un lugar puede definirse como lugar de identidad, relacional e histórico, un espacio que no puede definirse ni como espacio de identidad ni como relacional ni como histórico, definirá un no-lugar. La hipótesis aquí defendida es que la sobremodernidad es productora de no lugares, es decir, de espacios que no son en sí lugares antropológicos y que, contrariamente a la modernidad baudeleriana, no integran los lugares antiguos» (83); «los no-lugares son tanto las instalaciones necesarias para la circulación acelerada de personas y bienes (vías rápidas, empalmes de rutas, aeropuertos) como los medios de transporte mismo o los grandes centros comerciales, o también los campos de tránsito prolongado donde se estacionan los refugiados del planeta» (41).
} 
talmente superada por los medios audiovisuales, ha llevado a muchos creadores a buscar otros espacios y otras formas de expresión musical, una donde la palabra «música» no se ofrezca (ofrenda) como en Occidente, sino que se ofrezca, como en la cultura mapuche, como una expresión ritual colectiva sin cabida para el pasivo espectador.

La instalación inter-étnica genera un tipo de música espacial que muestra los rasgos de la nueva música indigenista: una música de una condición mestiza, (des)arraigada y afectada por una cultura global y con apertura hacia los logros técnicos de la música de arte contemporánea a la que des-pertenece. La instalación, es un arte-espacio nuevo, donde el espectador ya no está condenado a permanecer quieto en una butaca, por el contrario, en el ilusorio ambiente que rodea a la instalación, el espectador-auditor camina, observa, se acerca y aleja, se sienta o conversa con otros potenciales espectadores, en un punto de encuentro neutral, de algún modo desarraigado y pasajero. Un lugar que nunca más volverá a existir como tal.

Lo mismo ocurre con la calle, espacio propicio para la performance intercultural, especialmente en contextos de protesta, donde una nueva forma de festividad ritual, como la que ocurre todos los 12 de octubre en Santiago de Chile, irrumpe. Esta fecha convoca a una manifestación política y artístico-cultural a cargo de cofradías y grupos de bailes de los pueblos originarios de Chile.

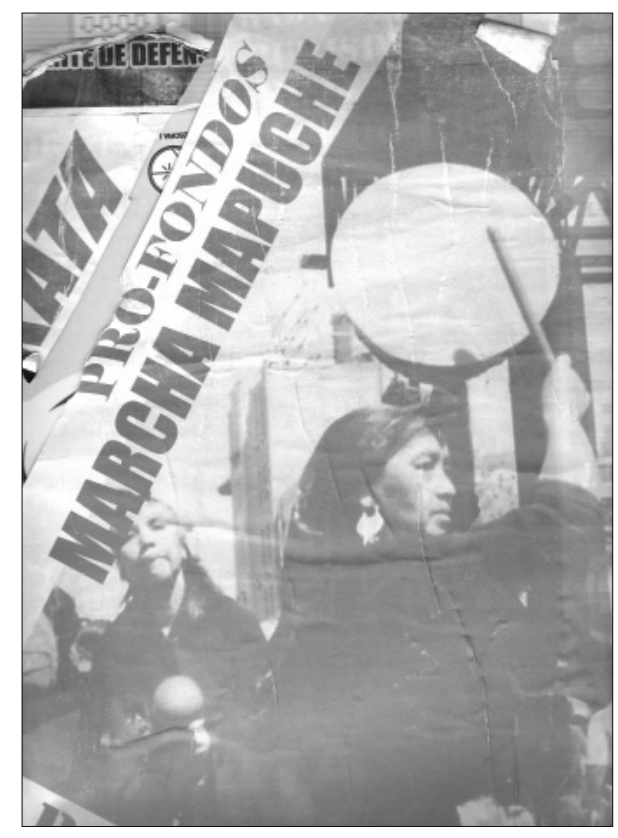

Afiche de marcha mapuche pro-fondos protesta. 12 de octubre del 2008.

La calle, en situación de la protesta, se transforma en el escenario de una performática musical vinculada a los pueblos originarios. La música que se pudo oír en el último acto del 12 de octubre del 2008 en Santiago, es una música que responde a los cánones de lo 
conocido como música indígena, la que es ejecutada por los instrumentos tradicionales y con el mismo vestuario ritual (como en el caso del mapuche y del atacameño y aymara); la diferencia está en que no nos encontramos en la vastedad ritual de la pampa araucana ni en la meseta altiplánica, sino en el terreno a-simbólico de la calle. La calle es el espacio para un encuentro efímero de grupos sociales que confluyen momentáneamente, convocados por un ideal común: la reivindicación de derechos de los pueblos minoritarios de Chile. Ahora no hay un santo ni una virgen por delante, es la bandera multicolor de los pueblos originarios la única imagen que se honra y venera.

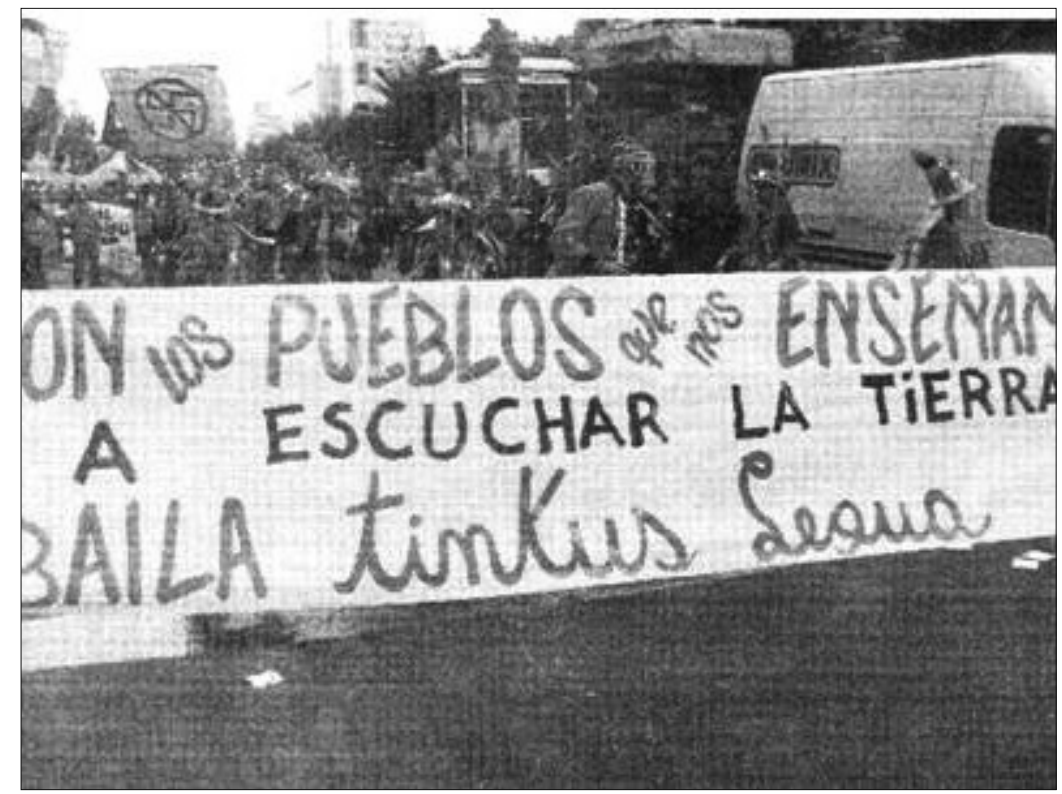

Cofradía de los Tinku acompañados por Agrupación Marka. Marcha de los pueblos originarios. 12 de octubre del 2008. 


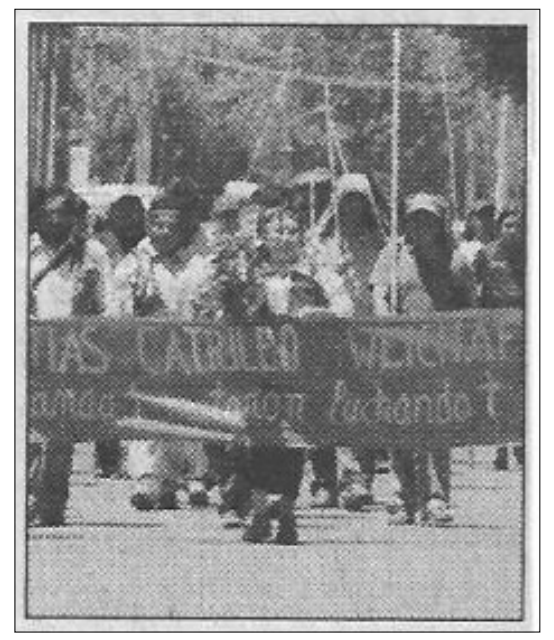

Marcha hacia la rogativa privada en la explanada del cerro Ñielol. El ceremonial de acceso restringido se reinstala en la sociedad del siglo XXI. Primer aniversario de la muerte de Matías Catrileo. Temuco, 2 de enero del 2009.

Es muy difícil establecer hoy en día, la línea de separación entre la actividad social y la acción de arte. Más aún en manifestaciones como las que involucran a los pueblos originarios, cuya acción social es imposible de separar de su ritualidad, de su performática musical y su cosmovisión espiritual. El Ngillatun privado realizado en la planicie del cerro Nielol, en la conmemoración de la muerte de Matías Catrileo, es un ejemplo de ocupación de un espacio público, con fines rituales, estableciendo condiciones de accesibilidad. La generación de un espacio privado en el vasto espacio de la intemperie, es la misma condición que dio origen a la sala de espectáculo y, con ella, a la institución del concierto. Hoy esta institución luce moribunda y obsoleta, pero la necesidad de ritualizar y sacralizar permanece. Para ello, el arte indígena hecho por indígenas ha sabido reinventar el espacio privado dentro del público, muy de la mano de los avances del arte espacial, especialmente, la instalación, la escultura-instalación y las artes audiovisuales. Estas nuevas formas de de-construir el espacio en el mismo espacio, es una forma de establecer en el antinatural lugar de la calle, una segunda naturaleza, la que, a la falta del espacio originario, resulta una estrategia de ocupación ritual válida para un pueblo ancestral que vive en diáspora. ${ }^{10}$

La necesidad de "ocupar», trajo de la mano nuevas estrategias de lenguaje y estructura artísticas. En Chile, este factor espacial repercute fuertemente a partir de los ochenta, época en que el compositor chileno busca otras formas de vincularse con la alteridad. Para ello, inicia trabajos de colaboración con artistas de otras disciplinas y de diferentes grupos étnicos, y, al mismo tiempo, encuentra en la fusión de las técnicas composicionales aborígenes con la escritura contemporánea un nuevo punto de encuentro. En estos

10 Sobre el elusivo límite entre el lugar conquistado por la cultura y el terreno silvestre, Augé sostiene que «el etnólogo [...] se vanagloria de poder descifrar a través de la organización del lugar (la frontera siempre postulada y balizada entre naturaleza salvaje y naturaleza cultivada) un orden tanto más coercitivo, y en todo caso evidente, en la medida en que su transcripción en el espacio le da apariencia de una segunda naturaleza» (2008: 49-50). 
años ochenta, de mucha circulación internacional como reacción al aislamiento cultural de un país que vivía en un régimen autoritario, la influencia de la cultura alemana, especialmente del teatro musical de Kagel y de las instalaciones de Joseph Beuys en las artes del espacio, repercuten directamente en la música chilena en general y de un modo especial en aquella de raíz indígena. Directamente influenciado por este paradigma alemán, se pasa a concebir lo que se sabe de la música del Otro como un dato abstracto, completo en sí mismo, a la manera de un arquetipo. En otras palabras, se intenta hacer del aborigen (el Otro) un objeto de composición. ${ }^{11}$

Sin duda el arte de Joseph Beuys y su escuela, fue importante en la gestación de un arte multimedial con raíz intercultural en Chile. Fue un paradigma de un tipo de arte que conducía a lo que hoy podemos llamar instalación multimedial, o incluso la performance, que no es más que (des)cubrir o experienciar la epifanía del arte en una situación social ordinaria. Hoy, nos encontramos viviendo una nueva especie de peregrinaje, uno que caracteriza a los centros de arte moderno del mundo, la gente circula por las salas de un museo esperando encontrarse, ya no con la inmóvil figura del cuadro, sino que más bien, espera deslizarse adentro de una «situación artística», que, como un aleph, la saque del horror del tiempo sucesivo, y la instale en un espacio-tiempo, de algún modo eterno y (des)conocido, como el One Way Colour Tunnel de Olafur Eliasson, que permite percibir aquello familiarmente extraño que caracteriza el unheimliche de la experiencia artística.

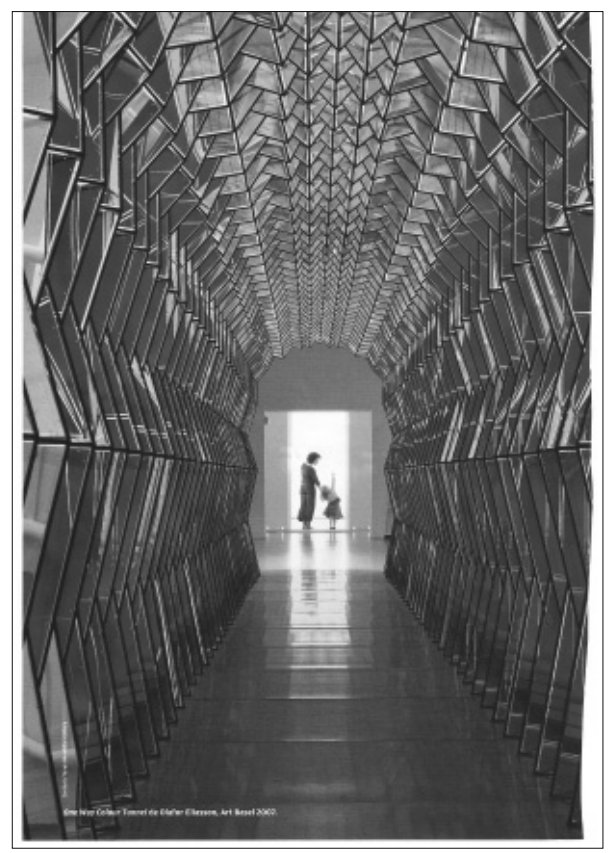

One Way Colour Tunnel de Olafur Eliasson. Art Basel, Suiza. 2007.

11 Como ejemplo, podemos citar la obra Exótica (1970-71) de Mauricio Kagel, en la que la creación de modelos sonoros orientales apócrifos, hace a la obra en sí, un arquetipo de la alteridad. No hay afán de resignificar lo genuino, sino trabajar una sonoridad ambiguamente «exótica», aprovechando la imposibilidad de definir el centro originario de este exotismo. En Chile, hubo intentos de este tipo, especialmente desde el terreno de la música para el teatro (por ejemplo, la música para El Guerrero de la Paz —1984_ de Gabriel Matthey). 


\section{LA NUEVA PEREGRINACIÓN}

Es esta especial coincidencia en el contexto social, que articula a los discursos indigenistas de los años cuarenta y los actuales, lo que me lleva a vincular una expresión que parece tender hacia lo mismo (reivindicar lo sagrado y sus «campos naturales» en un mundo despojado de sacralidad), pero, esta vez, las manifestaciones de este indigenismo ocurren en un espacio-tiempo cada vez más incierto y utópico. Se concurre a ellos, como a una peregrinación sin fe, en una frontera elusiva entre el ethos y la aisthesis, entre la performance y el ritual, devienen difusas y equívocas. Un caso de esto último, es la instalación Tierra dañada, creación interdisciplinaria con música del compositor chileno Cristián López. ${ }^{12}$ Tierra dañada, es una instalación de naturaleza interdisciplinaria, presentada en la segunda bienal de arte indígena, desarrollada en el Centro Cultural Palacio de la Moneda, en octubre del 2008. En ella participaron artistas visuales del área del video y de la escultura, un poeta, un iluminador y un compositor.

La instalación es una especie de gran tótem, hecho de monitores de televisión con la pantalla en gris (sin imagen), superpuestos unos sobre otros. Detrás de esta torre de monitores, en un plano posterior, se ve una pantalla horizontal que proyecta un video con imágenes en blanco negro. El video, muestra el éxodo de un grupo de hombres desnudos por una tierra baldía. Por momentos, el video se bifurca en dos imágenes, a la izquierda y derecha del espectador. La imagen de la izquierda muestra a un hombre desnudo, confinado en un callejón sin salida. En el suelo, alrededor de él, se ven esparcidos una serie de panfletos con el mismo poema escrito en ellos.

La estrategia inter-relacional de López, está en las antípodas de las empleadas en el arte multimedial de los ochenta. Aquí ya no hay la más mínima vinculación con estilemas $^{13}$ de raíz identitaria. La música de López para esta instalación es absolutamente electrónica. En ella, no hay ningún vestigio de material representativo de la cultura mapuche. La pieza electrónica está concebida con la técnica del eterno retorno, es decir, funciona permanentemente, sin cortes, y con la ilusión de la circularidad, porque, pese a que es una obra finita, no llega a percibirse nunca su recomenzar. El musema ${ }^{14}$ involucrado en esta música de López, es el chisporroteo eléctrico, y la caída de señal. Son pues, códigos musémicos provenientes de la tecnología, y del uso doméstico de ésta, no provienen estrictamente de la música, pero sí de un imaginario sonoro colectivo asociado al fallo, de un sistema, de un equipamiento, de un artefacto, de lo que sea, alude profundamente

12 La preceptiva estilística de Cristián López (1962) está marcada por su formación en música electrónica y música para medios visuales. Su opus es estilísticamente ecléctico y, en él, predomina la música de cámara para diversos medios instrumentales, el teatro musical multimedial, obras mixtas electrónicas y electroacústicas, y un gran número de obras destinadas a ser parte de montajes teatrales. Entre las obras más representativas de su estilo figuran Punta de riel (2000), montaje sonoro multimedial, la ópera TanGÓ (2002), y la ópera de cámara Leftraru, viajero ensoñado (2003), con textos del poeta chileno-mapuche Elicura Chihuailaf.

13 El estilema indica un ente musical que, por su frecuente uso por parte de los compositores, puede ser considerado como componente del estilo que caracteriza a un repertorio. Puede consistir en una configuración particular articulada en un parámetro musical — una sucesión de alturas, un encadenamiento de acordes, una sonoridad instrumental o vocal, etc.-, o en la concurrencia de varios - un acento obtenido con determinado timbre, un tipo de figuraciones rítmicas emitidas por un instrumento concreto, un ornamento vocal colocado en un punto particular de la macroestructura.

14 Musema es un término proveniente de la teoría semiológica, y se puede definir como un arquetipo individual de afecto musical codificado y puede actuar en tres roles diferentes: como «señal», como preparación afectiva y como identificación mnemónica. 
a todo aquello que, en nuestra sociedad, presta algún servicio y termina por fallar. El sonido frío, amnésico del C-Sound, se integra homogéneamente con el hormigueo en las pantallas de los monitores. Sin embargo, el apilamiento vertical de monitores, tiene directa relación con una imagen recurrente de la cultura mapuche: la figura del rewe, que es el palo o árbol sagrado de la machi, que en algunos lugares también se encuentra en el campo ceremonial (Catrileo, 1996: 205). Este tótem de monitores con la señal caída, es una metáfora directa de aquel otro, al que se refiere María Catrileo:

el tótem de machi que se planta frente a la puerta oriental de la casa. Es un tronco descortezado de laurel, maki o canelo que se planta en el suelo y se adorna con colihues y otras plantas. Tiene entre cuatro y siete peldaños que indican el número de poderes con que los dioses dotan al machi para enfrentar los males (1996: 233).

Como toda instalación de inmanencia originaria, Tierra dañada crea en torno a sí un eco-sistema particular, el que contiene las cuatro nociones esenciales de un lugar antropológico: el itinerario, la intersección, el centro y el monumento (Augé, 2008: 69). De estas cuatro nociones, la del monumento posee especiales connotaciones tratándose esta forma artística de una instalación. Según Augé, el monumento implica, etimológicamente, la expresión tangible de la permanencia, o, al menos, de lo que dura. En sus palabras:

sin ilusión monumental, a los ojos de los vivos la historia no sería sino una abstracción. La especie social está poblada de monumentos no directamente funcionales, imponentes construcciones de piedra o modestos altares de barro, ante los que cada individuo puede tener la sensación justificada de que, en su mayor parte, lo han preexistido y lo sobrevivirán. Curiosamente una serie de rupturas y de discontinuidades en el espacio es lo que representa la continuidad temporal (2008: 65-6).

El efecto de encantamiento que genera en el hombre un tipo de construcción espacial como la instalación, puede deberse sin duda a la carga totémica que posee. Más aún si el monolito posee la carga semántica de lo atemporal, y sólo la materialidad cultural aborigen en Chile posee esa condición. En el caso de Tierra dañada, la materia orgánica del rewe hecho de la madera espiritual del canelo, por tanto imperecedero, deviene en el inorgánico monitor de televisión descompuesto, que representa al poder eclipsado, de algún modo, extinto, y la música es la sobre-metáfora de la imposibilidad de «conectar», con esa inmanencia que es la fuerza espiritual de un pueblo acorralado: 


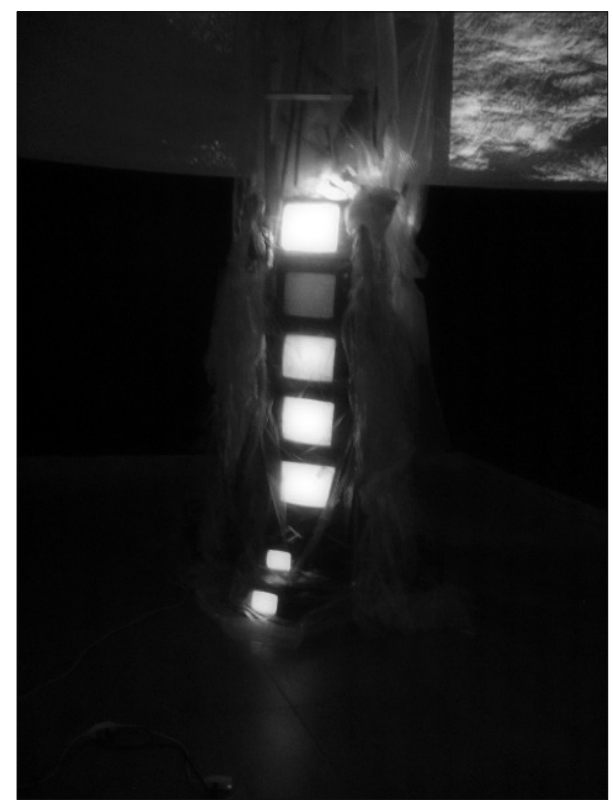

Tótem de monitores con la señal caída en la instalación Tierra dañada. Segunda bienal de arte indígena. Centro Cultural Palacio de la Moneda.

La imagen anterior muestra los siete peldaños del rewe, en un código tecnológico, digamos «industrial», que pone en relación «mimética» a un símbolo sagrado mapuche con el símbolo más sagrado de la sociedad sobremoderna: el televisor. La mimesis, trae una advertencia soterrada: si se reemplazan los rewes originarios por los rewes de la civilización occidental, el resultado no parece ser otro que el que muestra la imagen, terminar adorando a un objeto falible, perecible, impotente.

La cinta de audio de López es la proyección sonora de lo mismo, un espacio-tiempo baldío para la significación, para el encuentro. Cada chasquido de la base de audio, no genera consecuencias ruidísticas susceptibles de ser incorporadas en un "proceso" compositivo. El chasquido y el chisporroteo son, a la larga, todo el referente, la causa sin ningún efecto, la causa de ningún discurso encadenado. Esta puesta en escena de un terreno sagrado baldío, se potencia con el video proyectado en el plano inferior, filmado en colores malvas, sepias, blanco y negro: 


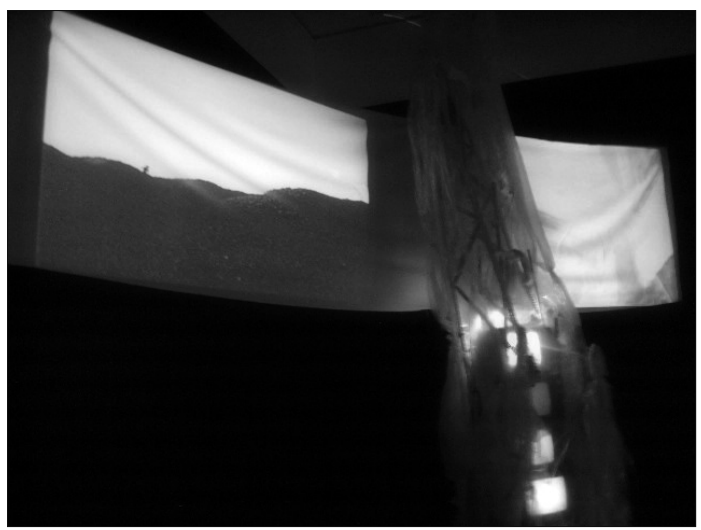

Instalación Tierra dañada. Video proyección posterior. Segunda bienal de arte indígena. Centro Cultural Palacio de la Moneda.

La radical abstracción sonoro-visual del montaje, se abre hacia un dato más concreto con la casi clandestina presencia del poema-panfleto formando la cruz mapuche en suelo que rodea a la instalación.

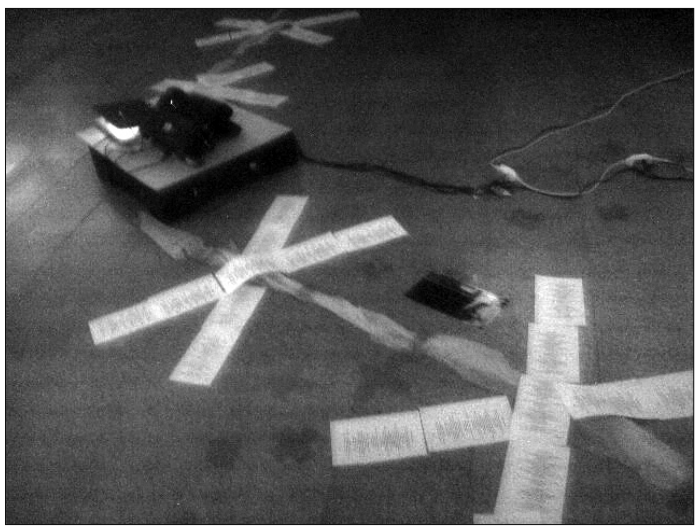

Instalación Tierra dañada. Poema-panfleto. Segunda bienal de arte indígena.

Centro Cultural Palacio de la Moneda.

El poema-panfleto ${ }^{15}$ dice:

\section{Tierra dañada}

Ya no sólo por ahí, por aquellos callejones barrosos, por esas humedades contradictorias de señales

\footnotetext{
15 Fragmento del poema recogido en el piso de la instalación Tierra dañada.
} 
que abrazan y sepultan, acarician, traicionan, envuelven...

Ya no sólo por las hojas que ya no están, los humos que se fueron ayer, el silencio que arrecia en las nubes, en las piedras que hablaron al infinito, arremolinado de retumbares

y palabras descascaradas...

matriz doblegada al círculo de las horas,

delgado cascajo...

también aquí en las esquinas que encubren los secretos, cuerpos encorvados, gritos inalámbricos,

varias escrituras, rostros adoquinados...

Espíritu malo que tuerce la mirada y oblicua las sonrisas,

las miradas, los ecos.

Quebranta las custodias,

el escueto estar...

Namku

\section{LA INTERVENCIÓN DEL ESPACIO PÚBLICO}

Francisco Huichaqueo ${ }^{16}$ explora nuevas propuestas de arte digital que conectan, a través de soportes mixtos, el presente con el pasado, la cultura ancestral, al artista y su vínculo con el paisaje, la urbe y la sociedad. El reciente trabajo audiovisual de Huichaqueo, se basa en la resignificación de la memoria oral del pueblo mapuche. Gente-pájaro (2008), nos llega en soporte de video con banda de sonido incorporada, música perteneciente a Mario Z (canción Anarky Plastic) y Pintor Z (Disco por fin), y con Graciela Nanculeo como intérprete de la canción interpretada en el movimiento II del audiovisual. A pesar de la validez del recurso, el soporte video de este audiovisual es un mero intermediario. La experiencia artística comenzó mucho antes, en el momento de descubrir y de ocupar los espacios para la performance del hombre-pájaro. Gente Pájaro, Che Uñum en Mapudungun, es un video-experimento que circula y deambula en los géneros del video arte, la performance y el video-clip. Esta compuesto por tres movimientos; el primero filmado en los bosques y en el borde del río de la ciudad de Valdivia, un atleta realiza un acto performático que fusiona el pakourt (deporte proveniente de las calles) con la expresión corporal orientada por el director, quien en el trabajo de postproducción le otorga sentido estético. El segundo está filmado en un set donde una mujer mapuche canta en mapudungun y es rodeada por tres bailarinas que interpretan, la imagen es intervenida

16 Originario de la ciudad de Valdivia, Francisco Huichaqueo (1977), artista visual y académico de la Escuela de Arte de la Universidad de Chile, admite que le han marcado los creadores Francisco Smythe y Víctor Hugo Bravo. Francisco Huichaqueo lleva ocho años desarrollando la animación digital. Ha producido 15 cortometrajes, ha expuesto y difundido su obra en la Bienal de Video y Nuevos Medios de Santiago, en el Concurso Kent Explora, la Galería Normal y la Enrico Bucci, también en el Museo de Artes Visuales «MAVI», Festival de cine de Valdivia y el Centro Cultural La Moneda.

En 2006, obtiene la Beca Amigos del Arte, en el área arte digital. Actualmente es Profesor de Animación en la Universidad de Chile. Destaca su participación en diversos festivales nacionales e internacionales. 
por elementos simbólicos provenientes de la cultura originaria del sur del continente. El tercer movimiento se desarrolla en las calles de Santiago por la noche, donde el actor se arrastra desarrollando un acto de poesía fuerte y auténtico, "restregando al opresor su prepotencia hacia él, una persona que tiene menos posibilidades de defenderse», aclara Francisco Huichaqueo. ${ }^{17}$

En las imágenes de Huichaqueo, la música es inseparable de la imagen y la imagen es inseparable del espacio. En el fondo, su arte video es un arte mediatizado, la situación artística ocurrió mucho antes de que llegáramos a verla en la imagen. El pasado regresa desde el presente cotidiano y del lugar conocido. Es un círculo atemporal en el que no es posible encontrar el comienzo. Para el etnomusicólogo el reto es mayor, pues se ve obligado a enfrentarse al nuevo soporte que emplea Huichaqueo, el video-clip, una especie de estructura musical apriorística con una preceptiva estilística ya decodificada, pues, el género, posee algo más de veinte años de antigüedad. El video-clip, recurso audiovisual generado por la industria de la música comercial, tiene en Huichaqueo, una aplicación distinta, en vez de servir para la implantación en el mercado de una matriz fonográfica, en el audiovisual de Huichaqueo sirve para estructurar una relación imagen-sonido desde una óptica intercultural. Las bases pregrabadas y el sonido MIDI, ${ }^{18}$ se utilizan deliberadamente para resituar el inmemorial relato de la tradición mapuche en un contexto urbano, sobremoderno y codificado universalmente por la MPU. ${ }^{19}$ El recurso del videoclip, que nació para contextualizar en imágenes el relato musical de la canción popular, normalmente adherida a situaciones vivenciales de las urbes modernas y del espacio público, es el fondo sonoro ideal para la ocupación de espacios públicos como el que hace Huichaqueo en la estación del ferrocarril de la ciudad de Valdivia, en cuyo escenario y en cuyos vagones semi-abandonados, despliega una arriesgada coreografía: la escena del ferrocarril, que transcurre en el primer movimiento del audiovisual. El epígrafe del movimiento es, "cuando una persona debe migrar, debe empezar de nuevo, debe abrir los ojos y mirar de otra forma ${ }^{20}$. El movimiento se abre con un pedal figurado de sonidos «sampleados», todo basado en un sistema modal propio del «pop-balada». Este pedal figurado sostiene una diversidad de señales sonoras: muestras de toquido de instrumentos mapuches (trutruka y pifülkas) extraídas de contexto, canto mapuche en voz de mujer, sonidos concretos (que aluden al medio ambiente del sur). Todas ellas flotan sobre este pedal de sonido MIDI, no generan sintaxis de continuidad, sólo aparecen y desparecen. La sonoridad global, el plan formal y las técnicas de collage sonoro involucradas, tienen directa relación con el género New Age. Se suma a ello, una temporalidad lisa, una dinámica pareja y suave y la utilización de fragmentos de sonidos con poder de arraigo identitario (muestras de audio de instrumentos mapuches). Los toquidos de pifülfas están cuidadosamente filtrados y editados, a veces, sufren el tratamiento de la astilla, que fragmenta la señal a un grado de hacerlo irreconocible. La base "sampleada» también soporta a un ostinato de kultrunes y kaskawilla junto al canto de mujer en mapudungun (canto de folclor mapuche). Este continuo sonoro, se mantiene sonando con la sensación del eterno retorno, siempre recurre al mismo eje modal.

\footnotetext{
Citado de una entrevista a Francisco Huichaqueo, publicada en la revista digital <www.escaner.cl>. MIDI, «musical internacional digital interfase», es el sistema de interfase de validez mundial entre teclados y computadores. Generó, a partir de los ochentas, una sonoridad digital característica de la música popular.

19 MPU, es la sigla de músicas populares urbanas.

20 Epígrafe extraído del primer movimiento del audiovisual Gente-pájaro, de Francisco Huichaqueo.
} 
Sobre esta base New Age, se puede ver la acrobática performance del hombre-pájaro sobre los vagones del ferrocarril:
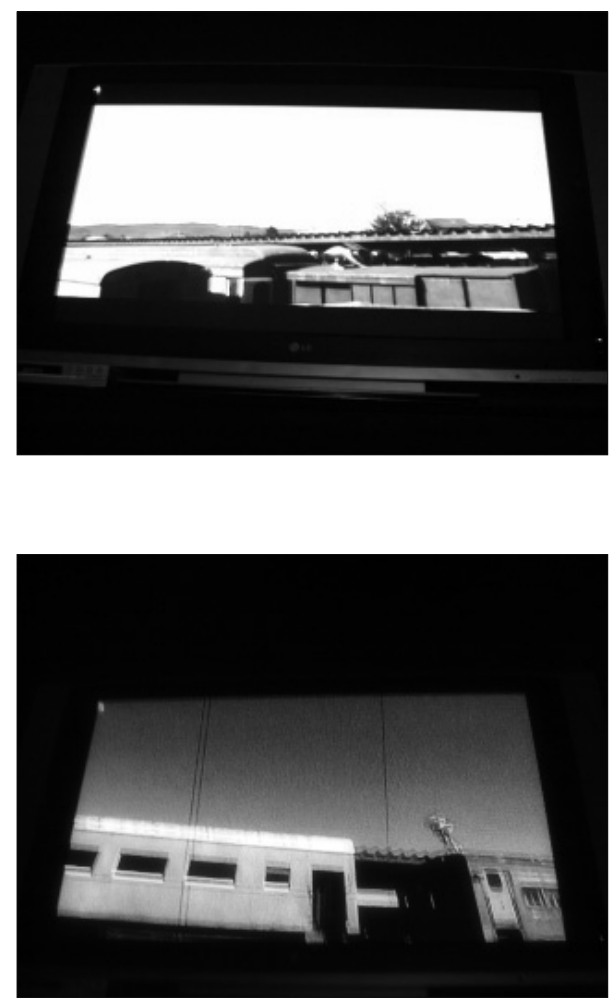

Intervención de la estación de ferrocarril de Valdivia. Salto de acróbata del hombre-pájaro. Gente-pájaro, Mov. I, de Francisco Huichaqueo.

Sobre los techos de estos vagones, se ve correr a un acróbata-actor saltando de carro en carro con una gracia y fortaleza física descollante. Este acróbata, en personaje de hombre-pájaro, es tomado por la cámara en un traveling permanente. El ritmo de la imagen, suave e imperceptible, logra captar vívidamente el gesto físico del acróbata, limpio, claro, preciso y virtuoso, una metáfora de la vitalidad y de la potencia de la espiritualidad mapuche expresada en la perfección y belleza de un cuerpo sano, joven y fuerte. El evidente deterioro de los vagones, fuera de uso, abandonados a su suerte, son el correlato perfecto para lucir esta flecha de vitalidad, que encarna el relevo de una caminata infinita, la de la creencia original. 


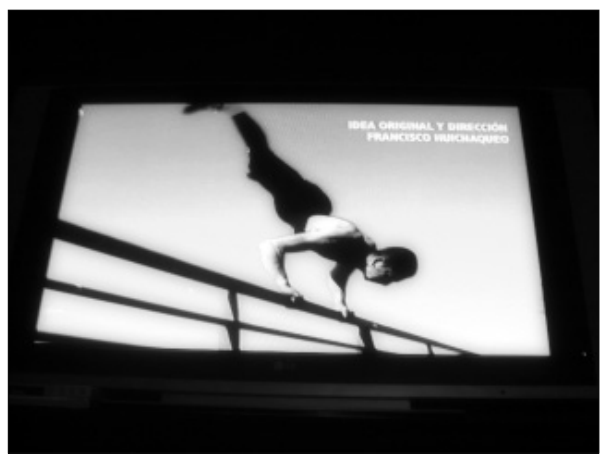

La fortaleza física como reflejo de una indomable fuerza espiritual. Actor-acróbata realizando pakourt en puente sobre el río Valdivia. Gente-pájaro, Mov. III, de Francisco Huichaqueo.

La música clip, que se deja oír en esta situación, sólo realza el gesto físico, no lo contradice, por tanto, no lo interviene ni lo interactúa. Son las tranquilas bandas del sonido New Age, las que imponen una temporalidad lisa, apulsativa, sin células rítmicas que interrumpan la metáfora del gesto limpio y continuo (Díaz, 2005: 73-4).

La intervención del espacio público puede asumir dimensiones más riesgosas. Ante la ocupación de un sitio estático, como la estación de ferrocarril de Valdivia, una estación que no espera a nadie, Huichaqueo opone la ocupación de la calle, un sitio que no ofrece garantías para su «ocupación» artística. El factor incierto de la coordenada calle, no es un problema para Huichaqueo, sino una variable más de una coordenada activa que reacciona a la ocupación. Huichaqueo utiliza este contexto, para metaforizar la indigna condición subalterna, vagabunda y huérfana del hombre-pájaro (ser indígena) al aterrizar en la urbe santiaguina. Todo el tercer movimiento del audiovisual, que contiene la ocupación de la calle santiaguina, está basada en un solo track de audio, una gran base D.J, ${ }^{21}$ es decir, una base sonora proveniente del género de música electrónica para baile. ${ }^{22}$ Este género, discotequero, que ha devenido a otros espacios más restringidos de realización, marca decididamente el tipo de sinestesia que plantea Huichaqueo. La pintura digital desarrollada y la urbana cualidad de las imágenes, sigue el tono y la dramaturgia de este tipo de base. El epígrafe del movimiento es: «el éxodo como condena». ${ }^{23}$ Hay intervenciones raperas, todo el tiempo, que van preparando la transformación del hombre-pájaro en hombre-perro. Entre algunas, se pueden citar: «el hombre condenado al trabajo, a la pelea, y a la guerra». ${ }^{24}$ Las señales de entrada y salida más recurrentes son las voces de Salvador Allende y Augusto Pinochet. Estas señales poseen la virtud de incorporarse al swing de la base con muy poca elaboración. Sólo la voz de Pinochet es tratada con un factor de delay. La voz de Allende se deja oír claramente con el speech, «los artistas están con nosotros». ${ }^{25}$

\footnotetext{
Disc-jockey.

Dance electronic.

Epígrafe extraído del primer movimiento del audiovisual Gente-pájaro, de Francisco Huichaqueo.

Citado del primer movimiento del audiovisual Gente-pájaro, de Francisco Huichaqueo.

Citado del tercer movimiento del audiovisual Gente-pájaro, de Francisco Huichaqueo.
} 


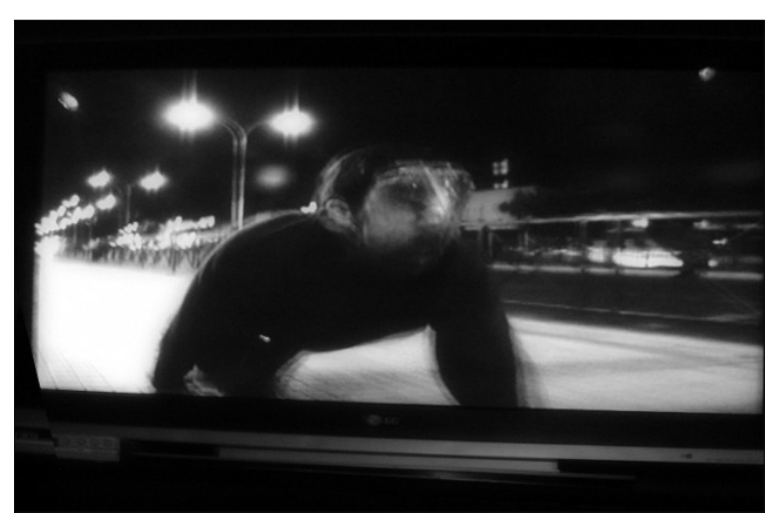

Hombre-pájaro deviene en hombre-quiltro, vagando por las calles de Santiago. Gente-pájaro, Mov. III, de Francisco Huichaqueo.

El movimiento II, sobre imágenes de aves errantes, mujeres vestidas de negro, matrimonio de mapuches vestidos con trajes de huinka, se oye una banda de audio con sonidos de edición digital, combinados con sonidos de sintetizadores y fugaces destellos de sonidos concretos (voces de gente en fiesta, ruido de viento en el follaje de los árboles, el sonido desafinado de una guitarra campesina), todo tratado como un gran cantus firmus, intervenido con los recursos de edición del loop y del sonido "astillado». ${ }^{26} \mathrm{La}$ situación central de este movimiento, es un casting, más o menos espeluznante, protagonizado por tres mujeres vestidas de negro. Una de ellas, canta a capella, una monodia en mapudungun. La monodia es un tipo de folclor de raíz mapuche, probablemente la folclorización del canto de machi puesta en formato pop new-age. El texto traducido dice:
por el camino de un cerro, yo voy $[\ldots]$
encontré una cueva de peken,
y me trató de decir algo con el mover de su cola
y su canción propia como rechazándome,
al reprenderlo yo, el peken no habló,
no habló, no habló el malvado peken
al estar de rodillas yo, el malvado peken no habló. ${ }^{27}$

El planteamiento formal de base de audio en este movimiento, responde a un patrón de forma canción propio del pop: A (sonido editado-sintetizado); B (monodia de folclor mapuche); A' Coda (breve reaparición del sonido sintetizado superpuesto a la parte final del canto mapuche). El casting es puesto deliberadamente en contrapunto con el material de mayor valor identitario (el canto en mapudungun), esto sirve para realzar el carácter utilitario, de comercio de la identidad humana que posee la situación del casting, cuyo vacío ontológico, puesto en el no-lugar del set de televisión, sólo puede ser llenado con la carga semántica de la lengua original, la que devuelve el ser a quien la habla.

\footnotetext{
26 Pequeños fragmentos de sonido extraídos y dispuestos al azar de una muestra de sonido mayor.

27 Texto extraído del segundo movimiento del audiovisual Gente-pájaro, de Francisco Huichaqueo.
} 


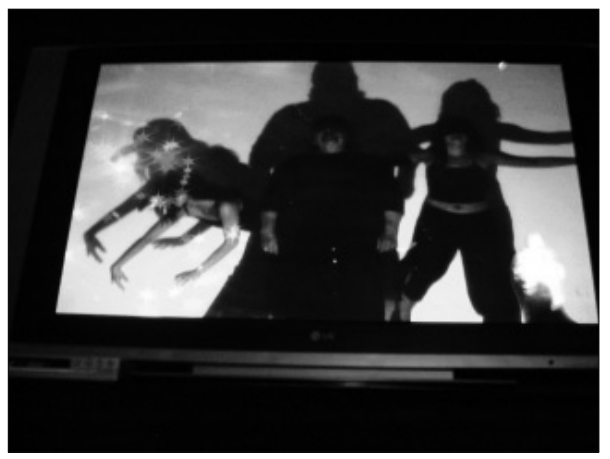

Mujer mapuche canta en mapudungun rodeada por tres bailarinas. Gente-pájaro, Mov. II, de Francisco Huichaqueo.

\section{CONCLUSIONES}

El arte musical indígena, hecho por el indígena, ha llegado a un cruce de caminos, en donde todos los sentidos son posibles, y donde incluso los destinos también pueden llegar a ser los lugares de tránsito. El arte de las culturas originarias es particularmente sensible a los paisajes y a los espacios, es en ellos donde se originó, y los actuales descendientes de estos pueblos que cultivan el arte musical en Chile, han asumido esta búsqueda de una intemperie propicia para una situación artística que no ha estado nunca desligada de su espacio. Las estrategias de sobrevivencia del arte indígena se han diversificado, la tecnología, los medios audiovisuales y la cultura web son los soportes de esta nueva espiritualidad, soportes que contienen en sí mismos, otra temporalidad, y, especialmente, otra espacialidad, una que desborda con largueza los gastados límites del salón de conciertos. En cierto modo, el no-lugar ha sido siempre la estrategia de supervivencia del arte indigenista en Chile. Su carácter minoritario, contravanguardista y anacrónico, lo ha llevado siempre a buscar (y ocupar) el lugar que no existe para él. Así lo fue en los treintas del siglo pasado, en los tiempos del indigenismo de Isamitt, en que la des-elitización del arte académico fue una consecuencia del ascenso de la clase media. Hoy, en pleno siglo XXI, es el ascenso de la mass media, el que penetra todo sistema cultural con la web, popularizando la aldea global del mundo y sus etnicidades. Súbitamente el marginal, el "excéntrico", asciende a un posicionamiento cultural masivo porque su propio carácter minoritario lo vuelve objeto del deseo para la red global que todo lo conoce y lo difunde. Recursos artísticos como la instalación audiovisual, la performance, el arte web, la intervención del espacio público, la restricción de los mismos con un fin artístico-ritual, son las nuevas estrategias del arte indigenista, y los espacios donde este acontece, son los nuevos espacios de hombre occidental, lugares de paso, funcionales, vacíos de carga antropológica, que súbitamente son transformados en espacios de resonancia ontológica 
por obra y gracia de un arte especial (y espacial), uno que opone a los sobrevalorados soportes amnésicos del arte occidental, las formas, sonidos y espacios cargados de memoria ancestral.

Son los nuevos retos para el etnomusicólogo también, el Otro ha llegado a la ciudad, y llegó para quedarse. Los géneros y medios musicales ya no son los de los pueblos originarios, por el contrario, son los mismos que utiliza el hijo del etnomusicólogo para divertirse con sus amigos. El indígena podría estar en estos mismos momentos, interviniendo la plaza que está en frente de la casa del etnomusicólogo, para desplegar una acción de arte integral, en donde el sonido MIDI, la amplificación cuadrafónica y el video-clip son la nueva substancia para una misma circunstancia, y el lugar común del parque, el eviterno espacio de la pampa araucana.

\section{REFERENCIAS}

Augé, Marc. (2008). Los no lugares. Espacios del anonimato. Una antropología de la sobremodernidad. Barcelona: Gedisa.

Catrileo, María. (1996). Diccionario lingüístico-etnográfico de la lengua mapuche. Santiago: Andrés Bello.

De Certeau, Michel. (1990). Linvention du quotidien. 1. Arts de faire. París: Gallimard.

Díaz, Rafael. (2008). La excéntrica identidad mapuche de la música chilena contemporánea: del estilema de Isamitt al etnotexto de Cáceres. Cátedra de Artes, 5: 65-93.

-. (2005). El tiempo, liso, apulsativo, no fragmentario. ¿Nostalgia del Tiempo Eterno de Dios? Resonancias, 16: 71-84.

Guilbault, Jocelyne y otros. (1993). Zouk, World Music in the West Indies. Chicago y Londres: The University of Chicago Press.

González, Juan Pablo. (1993). Estilo y función social de la música chilena de raíz mapuche. Revista Musical Chilena, 47/179: 78-113.

Monjeau, Federico. (2004). La invención musical. Buenos Aires: Paidós.

Hall, Stuart. (1992). New ethnicities. En James Donald y Ali Rattansi (eds.). Race, Culture and Difference. Londres: Sage.

Huachiqueo, Francisco. (2008). Francisco Huichaqueo estrena Gente-pájaro. Obtenido el 3 de enero del 2009 desde <www.escaner.cl>.

Isamitt, Carlos. (1935). Un instrumento Araucano. La trutruka. Boletín Latinoamericano de Música. I/I: 43-46.

Ochoa, Ana María. (2002). El desplazamiento de los discursos de autenticidad: una mirada desde la música. Obtenido el 20 de diciembre del 2008 desde <http://www.sibetrans.com/trans/trans6/ochoa.htm>.

Rondon, Víctor. (2002). Música tradicional chilena de los 50. Archivo de música tradicional chilena de la Facultad de Artes de la Universidad de Chile. Santiago, CD Fondart. 
Stuchlik, Milan. (1973). Rasgos de la Sociedad Mapuche Contemporánea. Santiago: Ediciones Nueva Universidad.

Vila, Pablo. (2000). Interpellations, Narrative Identities and Popular Music. En Malena Kuss (ed.). Latin American Music. An encyclopedic history of music from South America, Central America, Mexico, and the Caribbean. 2 vols. Nueva York: Schirmer Books/Macmillan Library Reference.

Recepción: diciembre de 2008 Aceptación: marzo de 2009 